\title{
Trend Analysis of Rainfall, Temperature and Relative Humidity over Kathmandu, Nepal
}

\author{
A. Regmi, H. K. Sah, B. Adhikari, D. Pandit
}

Journal of Nepal Physical Society

Volume 7, Issue 4, December 2021

ISSN: 2392-473X (Print), 2738-9537 (Online)

JNPS ISSN:2392-473X (Print)

Editors:

Dr. Binod Adhikari

Dr. Bhawani Joshi

Dr. Manoj Kumar Yadav

Dr. Krishna Rai

Dr. Rajendra Prasad Adhikari

Mr. Kiran Pudasainee

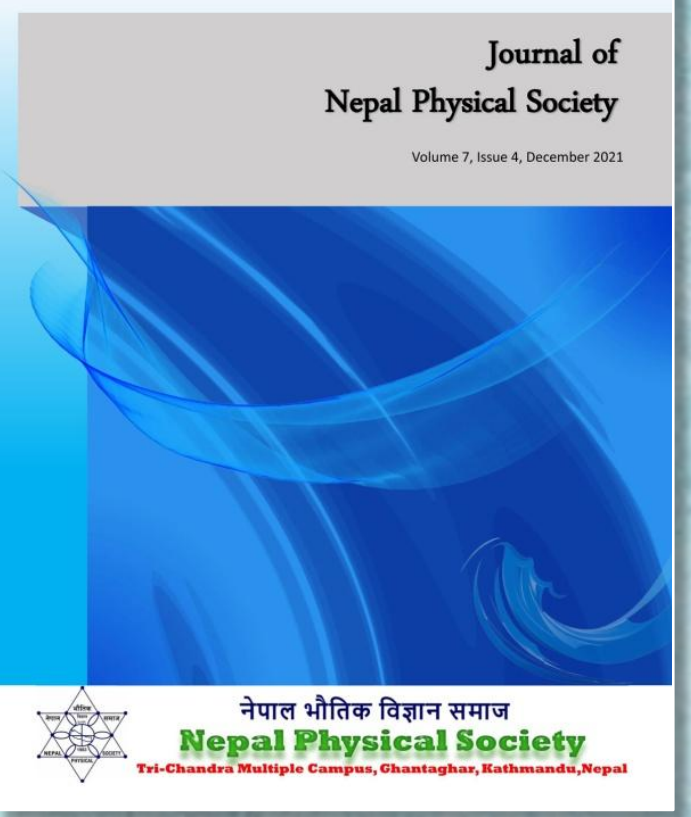

JNPS, 7 (4), 71-79 (2021)

DOI: http://doi.org/10.3126/jnphyssoc.v7i4.42934

Published by:

Nepal Physical Society

P.O. Box: 2934

Tri-Chandra Campus

Kathmandu, Nepal

Email: nps.editor@gmail.com 


\title{
Trend Analysis of Rainfall, Temperature and Relative Humidity over Kathmandu, Nepal
}

\author{
A. Regmi*, H. K. Sah, B. Adhikari, D. Pandit \\ Department of Physics, St. Xavier's College, Maitighar, Kathmandu, Nepal \\ *Corresponding Email: ashishregmi91@ gmail.com
}

Received: 12th November, 2021; Revised: 5th December, 2021; Accepted: 26th December, 2021

\begin{abstract}
Five years (2012-2016) data of Rainfall, Relative Humidity and Temperature from Tribhuvan International Airport Kathmandu, Nepal (TIA) station were analyzed. Nepal lies in the subtropical region in which experience four seasons in a year i.e., winter, spring, summer and autumn. The Mean, Correlation(r), And P-value were calculated to study the correlation between Rainfall, Relative Humidity and Temperature. Assuming the type I error alpha $(\alpha)$ as $5 \%$ the p-value was compared to it. T test was used to calculate the p-value. Assuming null Hypothesis $\left(\mathrm{H}_{0}\right)$ to show insignificant relation between two variable and alternative hypotheses $\left(\mathrm{H}_{1}\right)$ to show significant relation between two variables. The monthly analysis also shows the period of Highest Rainfall, Temperature and Relative Humidity Between June or July or August for the location of TIA Kathmandu, Nepal. The relation between Rainfall vs Relative Humidity and Relative Humidity vs temperature was found to be insignificant respectively throughout all five years. The relation between Rainfall and Temperature was found to be significant throughout all five years.
\end{abstract}

Keyword: Sub-Tropical, Correlation, P-value, Significant, Insignificant, meteorological parameters.

\section{INTRODUCTION}

The quantity of moisture in the air compared to what the air can contain at a given temperature is known as relative humidity. When the air is saturated, the relative humidity is at its highest. When the air is saturated, water vapor in the air condenses, resulting in the creation of microscopic water droplets. A cloud is made up of millions of these small water droplets. Such water droplets mix under particular conditions to generate large rain drops, which fall as rain owing to gravity [1]. Weather is the word used to describe the condition of the atmosphere at a specific moment and location, which is continually changing from hour to hour and from day to day. Climate is the longterm average condition of the atmosphere near the earth's surface. Temperature, precipitation, humidity, air pressure, and wind direction and velocity are all factors to consider. The climate of each nation is influenced by its geographical location (latitude, coastal or continental position) and physical environment. [2]. Because Nepal is located in the subtropical zone, it has four seasons throughout the year: winter, spring, summer, and autumn. The climatic type in any location associated with a specific time of year is known as the season. The fundamental cause of seasonal variation is a shift in the angle of the earth's axis in respect to the position of the sun at a given location. The months of January, February, and December are known as the winter months because they have the least amount of rainfall and the lowest temperature and humidity. The months of March, April, and May are known as spring months because of the rise in temperature, rainfall, and humidity. The summer months of June, July, and August are known for their excessive rainfall, warmth, and humidity. Autumn is defined by a reduction in temperature, rainfall, and humidity in the months of September, October, and November. Kathmandu, Nepal's capital, is located in the center section of the country (latitude: $27^{\circ} 45^{\prime} \mathrm{N}$, 
longitude: 85020 ' E) at an elevation of 1400 meters and is surrounded by four hills with elevations exceeding 1350.0 meters. [1]. The physical quantity that expresses heat and cold is temperature. The Earth has two hemispheres, one in the north and one in the south. When the earth rotates in its orbit for half a year, the northern hemisphere is tilted toward the sun, while the southern hemisphere is inclined in the opposite direction. As a result, the northern hemisphere receives the sun's harshest rays, causing the northern hemisphere's temperature to rise. Because the south hemisphere is closer to the sun, the temperature in the south hemisphere is higher than in the north. The geological temperature changes as a result of these phenomena [3]. On June 21, the Northern Hemisphere tilts closer to the sun, making it the longest day, and on December 21, the Southern Hemisphere tilts farther away from the sun, making it the shortest day, and vice versa. [4]. Because of the high temperature, the air at ground level rises and the colder air descends. The humidity varies as the temperature rises because the little air vessel expands and the volume of the vessel expands, containing more water vapor and lowering humidity. The air at ground level rises due to the high temperature, while the colder air falls. Because the tiny air vessel expands as the temperature rises, the volume of the vessel expands, containing more water vapor and lowering humidity. And when the temperature drops, the air vessel shrinks, reducing the volume of the vessel, which means it holds less water vapor, indicating high humidity. Air that is cooler has a lower potential to absorb water vapor, and vice versa. In the summer, eastern air flows via the Bay of Bengal, causing monsoon, while at the winter, western air flows through the west side of the country, lowering the temperature and causing snowfall in the higher elevations. Here in $2^{\text {nd }}$ chapter, we discuss about the arrangement of the data and the method of analyzing it. In the $3^{\text {rd }}$ chapter we discussed about the result with the graph and in the $4^{\text {th }}$ chapter we discussed the conclusion.

\section{DATASET AND METHODOLOGY}

\subsection{Dataset}

In this paper we have taken three parameters of data from Meteorology and Hydrology department of Nepal, which are Rainfall, Temperature, and Relative Humidity from the period of year 20122016 of Tribhuvan International Airport Kathmandu, Nepal. The data was then transferred to MS-Excel where the further study and arrangement were done. The data contains the information of the parameters Rainfall in milliliters $(\mathrm{mm})$, temperature in Celsius (average temperature of Maximum and Minimum), the Relative Humidity in percentage (\%). Arrangement of data was done according to our objectives. The first arrangement was done by calculating the mean data of each month for the year 2012-2016 respectively. The correlation analysis was made by the same data that we arranged for monthly analysis. The t-test performed was conducted in MS-Excel and calculated the p-value.

\subsection{Methodology}

Correlation is a statistical term that describes how two or more variables are related [5]. Positive, Negative, and Neutral correlation are the three most common signs of correlation employed in basic interpretation. When two variables move in the same direction, the correlation is called positive correlation. When two variables move in opposite directions, the correlation is called negative correlation. It's called neutral correlation when there's no relationship between two variables [6]. A correlation has three forms they are, Linear, non-linear, and Monotonic. A correlation is linear when the two-variable change at constant rate and satisfy the equation of slope $\mathrm{Y}=\mathrm{mx}+\mathrm{c}$. A correlation is non-linear when the two variables don't change at a constant rate. In this case the relationship between these variable shows a curve line pattern like parabola, hyperbola etc. A correlation is monotonic when the variable tends to move in same direction but not at a constant rate. So, we can say that all linear correlation is monotonic but the opposite is not always true [7]. There are several types of correlation coefficient but here we use Pearson correlation coefficient (r). It is used to measure strength and direction of linear relationship between two variables [8]. The alternative hypothesis is always what we are trying to prove. The null hypothesis is the hypothesis that we are always trying to provide evidence against. In our case we are trying to provide the evidence against the hypothesis that there is no significant linear correlation between two variable [9]. T test also called student $\mathrm{T}$-test is an inferential statistic that allows to use sample data to generalize an assumption to an entire population [10]. A p-value is the probability that the null hypothesis is true. Considering level of significance $5 \%$ we can make the interpretation that if the p-value is smaller than the significant 
value we reject the null hypothesis and if the pvalue is greater than the significance value we fail to reject the null hypothesis [11].

\section{RESULT AND DISCUSSION}

Result of monthly variation and correlation between rainfall, temperature and the relative humidity for the year (2012-2016) are mentioned here.

\subsection{Monthly variation}

Here in figure 1 , we can see the monthly variation of rainfall, temperature and relative Humidity from year 2012-2016. Light blue color indicates the year 2012, orange color indicates the year 2013, silver color indicates the year 2014, yellow color indicates the year 2015 and dark blue color indicates the year 2016. The first graph it shows the monthly variation in rainfall. $\mathrm{X}$-axis denotes the months while $\mathrm{Y}$-axis denotes the average rainfall in millimeter. The highest average rainfall observed in this graph is in the month of July and lowest average rainfall is observed in the month of Janaury. Here the flow of each year in the graph is quiet similar to each other. There may be small difference in the amount of rainfall but the tendetive pattern is been followed by each year. Nepal faces moonsoon in the month of mid june to august and we can see in the graph that at these month there is increase in average rainfall. Rest of the year is quiet dry than to the month of rainfall so we can see less average rainfall in other months.

The second graph, we can see the monthly variation of temperature. The $\mathrm{X}$-axis denote the months while $\mathrm{Y}$-axis denote the average temperature. Here average daily temperature is calculated by taking mean temperature of max and min temperature. We can see that the high temperature was recorded in the month of June July and August. Which also state that these months are referred as summer seasons. The winter months of December, January, and February are marked by cold temperatures and are referred to as the "winter months". Earth has two hemispheres Northern and Southern. Nepal lies in Northern Hemisphere. When the Northern hemisphere of the earth tilts toward sun we experience longer days and the temperature also rises. Same as when northern hemisphere of the earth tilts away from the sun we experience low temperature and day is shorter. Northern hemisphere contains more land than the southern hemisphere. This geographic condition causes the temperature of northern hemisphere be more than the southern hemisphere. The land heats up quickly and cools down quickly. Due to this condition northern hemisphere record high temp and low temp in summer and winter respectively than to the southern hemisphere.

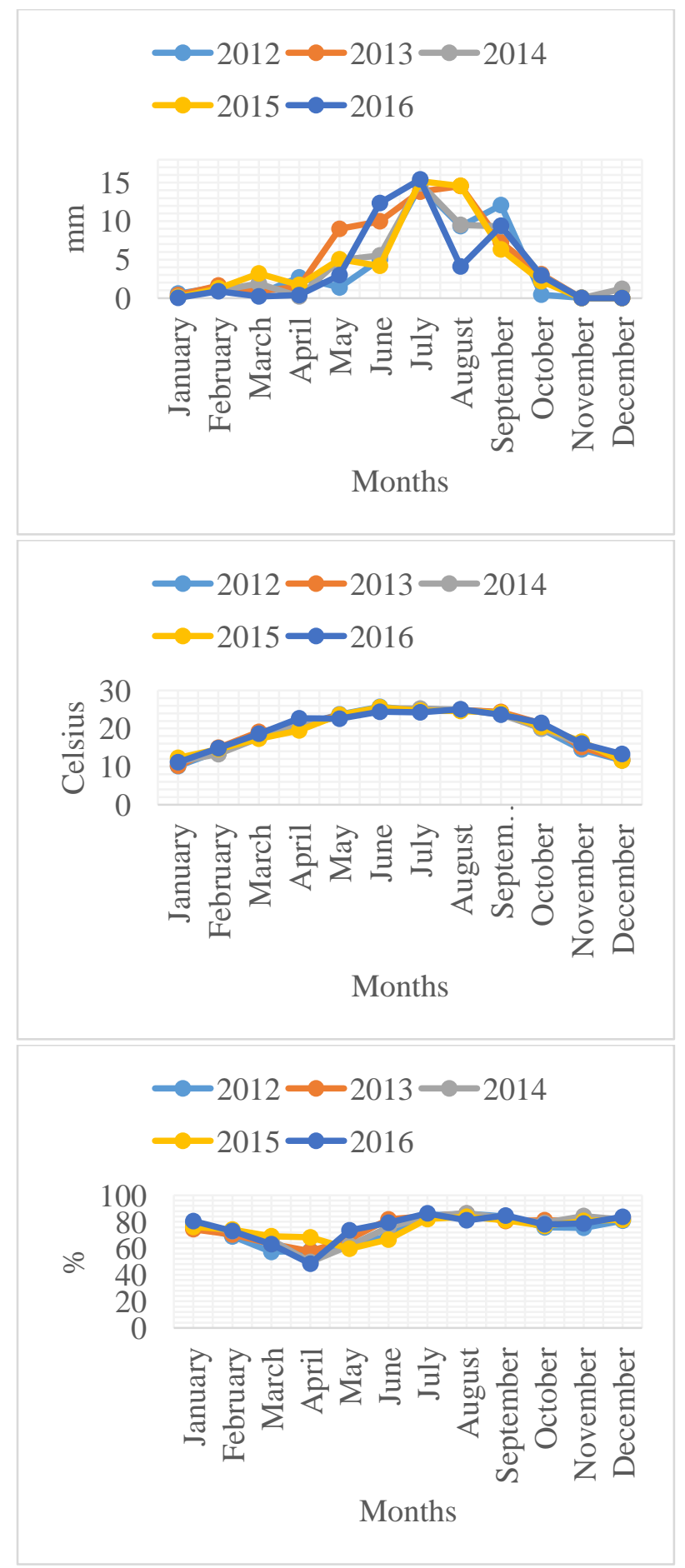

Fig. 1: Monthly variation of Rainfall, Temperature and Relative Humidity. 
The third graph, we can see the monthly variation in relative humidity. The $\mathrm{X}$-axis denotes the months while $\mathrm{Y}$-axis denotes the percentage of air saturation. The high RH recorded in the month of summer July and August. While low RH recorded in the month of spring March, April and May. Humidity depends upon temperature and pressure. Since the pressure is constant at this region, we neglect the condition [1]. But when temperature increases the capacity of air molecule absorbing the water molecule increases and vice versa [3]. Due to this nature or dependency, we can see the sudden drop in RH in the month of spring due to increase in temperature [4]. In winter the RH are quite high because when the temperature increase in day the air molecules absorbs as much as it can. And when there is sudden decrease in temperature its stats to condense after reaching $100 \%$ saturation state. The temperature at which the air is $100 \%$ saturated is called Dew point temperature [4]. If the temperature decreases below the dew point, then the condensation process begins and there is fog, dewfall etc. Dew to this phenomenon we have high $\mathrm{RH}$ in winter than in spring. In spring when the temperature is high the dew point temperature lies quiet below than the normal temperature. In which air is not able to be $100 \%$ saturated to and start condensation.

\subsection{Correlation}

Here in figure 2 we can see the correlation between Rainfall vs Temperature, Rainfall vs RH, RH vs Temperature for the year 2012. The first graph is the correlation between Rainfall in $\mathrm{X}$-axis and Temperature in $\mathrm{Y}$-axis is 0.689 , which has the $\mathrm{p}$ value of 0.013 which is less than the significance level $\alpha$ (0.05) which further reject the null hypothesis stating that the correlation between them is significant moderate positive correlation. The second graph is correlation between Rainfall in Xaxis and Relative Humidity in Y-axis is 0.564, which has p-value of 0.055 which is greater than the significance level $\alpha(0.05)$ which further does not reject the null hypothesis stating that the correlation between them is insignificant moderate positive correlation. The third graph is for correlation between Temperature in $\mathrm{X}$-axis and Relative Humidity in Y-axis is 0.047 , which has the p-value of 0.884 which is greater than the significance level $\alpha(0.05)$ which further does not reject the null hypothesis stating that the correlation between them is insignificant negligible positive correlation.

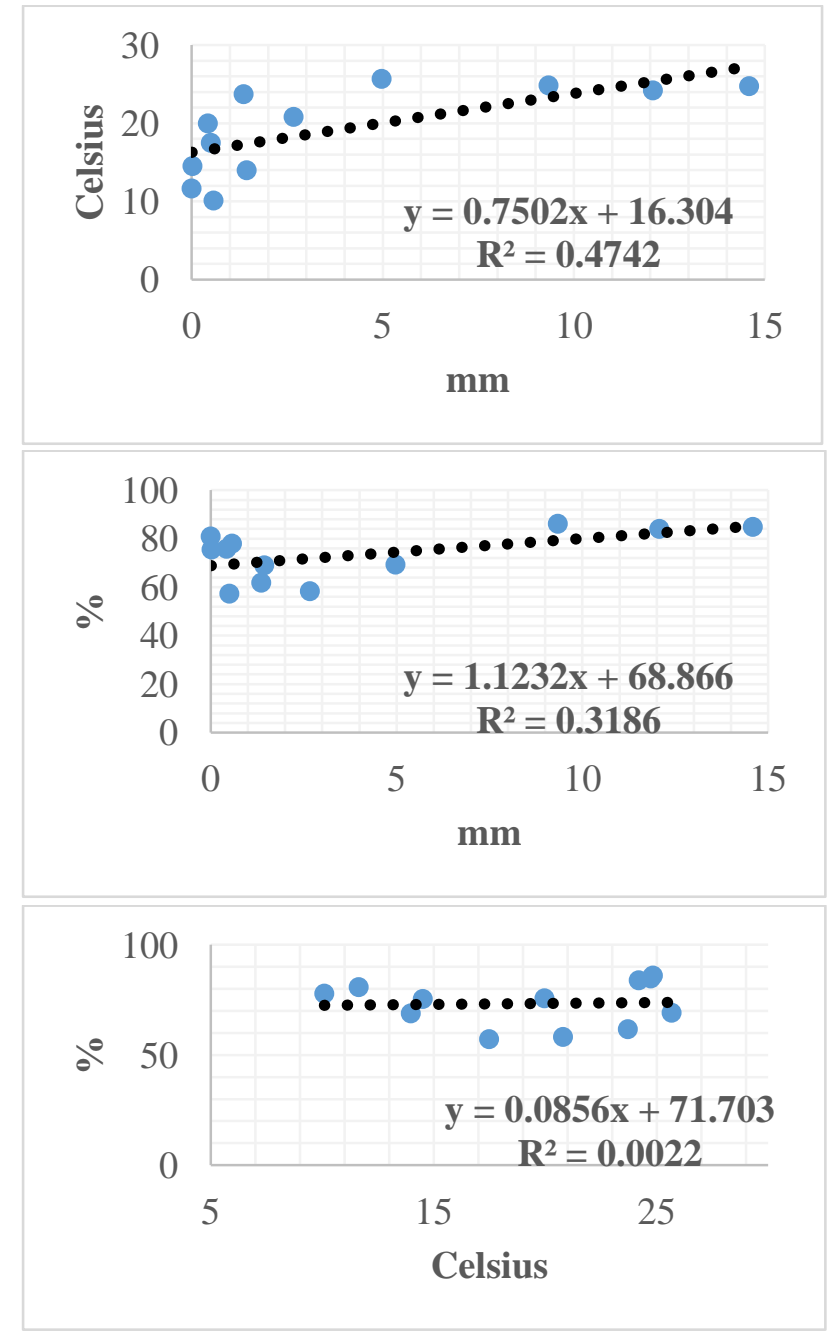

Fig. 2: Shows the correlation between Rainfall vs Temp, Rainfall vs RH and RH vs Temp for the year 2012

Here in figure 3 we can see the correlation between Rainfall vs Temperature, Rainfall vs $\mathrm{RH}, \mathrm{RH}$ vs Temperature for the year 2013. The first graph side is the correlation between Rainfall in $\mathrm{X}$-axis and Temperature in $\mathrm{Y}$-axis is 0.818 , which has the $\mathrm{p}$ value of 0.001 which is less than the significance level $\alpha$ (0.05) which further reject the null hypothesis stating that the correlation between them is significant high positive correlation. The Second graph is the correlation between Rainfall in X-axis and Relative Humidity in Y-axis is 0.445 , which has $\mathrm{p}$-value of 0.146 which is greater than the significance level $\alpha(0.05)$ which further does not reject the null hypothesis stating that the correlation between them is insignificant low positive correlation. The third graph is the correlation between Temperature in $\mathrm{X}$-axis and Relative Humidity in Y-axis is 0.134 , which has the p-value of 0.677 which is greater than the significance level $\alpha(0.05)$ which further does not reject the null 
hypothesis stating that the correlation between them is insignificant negligible positive correlation.

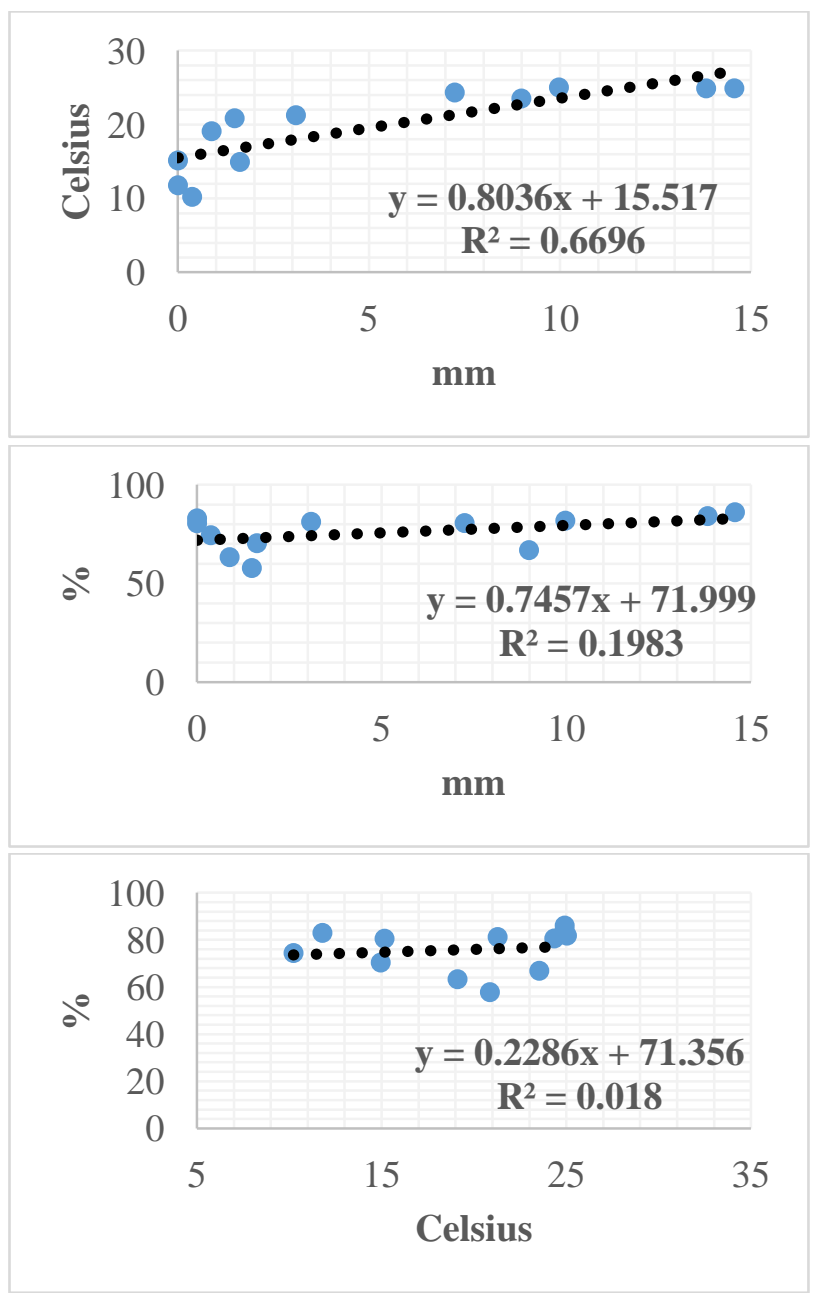

Fig. 3: Shows the correlation between Rainfall vs Temp, Rainfall vs RH and RH vs Temp for the year 2013

Here in figure 4 we can see the correlation between Rainfall vs Temperature, Rainfall vs RH, RH vs Temperature for the year 2014. The first graph is the correlation between Rainfall in $\mathrm{X}$-axis and Temperature in Y-axis is 0.771 , which has the $\mathrm{p}$ value of 0.003 which is less than the significance level $\alpha$ (0.05) which further reject the null hypothesis stating that the correlation between them is significant high positive correlation. The second graph is the correlation between Rainfall in X-axis and Relative Humidity in Y-axis is 0.416 , which has p-value of 0.178 which is greater than the significance level $\alpha(0.05)$ which further does not reject the null hypothesis stating that the correlation between them is insignificant low positive correlation. The third graph is the correlation between Temperature in $\mathrm{X}$-axis and Relative
Humidity in $\mathrm{Y}$-axis is 0.001 , which has the p-value of 0.998 which is greater than the significance level $\alpha(0.05)$ which further does not reject the null hypothesis stating that the correlation between them is insignificant negligible positive correlation.

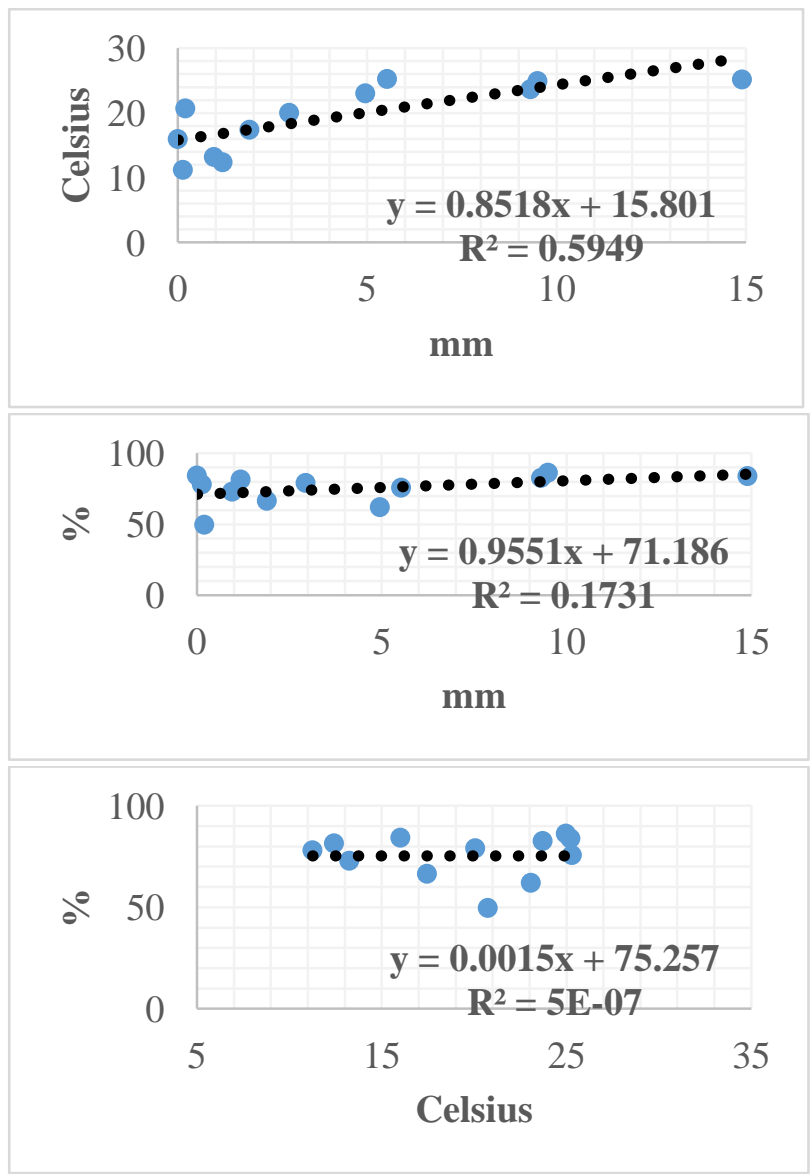

Fig. 4: Shows the correlation between Rainfall vs Temp, Rainfall vs RH and RH vs Temp for the year 2014.

Here in figure 5 we can see the correlation between Rainfall vs Temperature, Rainfall vs RH, RH vs Temperature for the year 2015. The first graph is the correlation between Rainfall in $\mathrm{X}$-axis and Temperature in Y-axis is 0.728 , which has the p-value of 0.007 which is less than the significance level $\alpha$ $(0.05)$ which further reject the null hypothesis stating that the correlation between them is significant high positive correlation. The second graph is the correlation between Rainfall in X-axis and Relative Humidity in Y-axis is 0.307 , which has p-value of 0.331 which is greater than the significance level $\alpha$ (0.05) which further does not reject the null hypothesis stating that the correlation between them is insignificant low positive correlation. The third graph is the correlation between Temperature in $\mathrm{X}$-axis and Relative Humidity in Y-axis is -0.147 , which has the 
p-value of 0.649 which is greater than the significance level $\alpha(0.05)$ which further does not reject the null hypothesis stating that the correlation between them is insignificant negligible negative correlation.
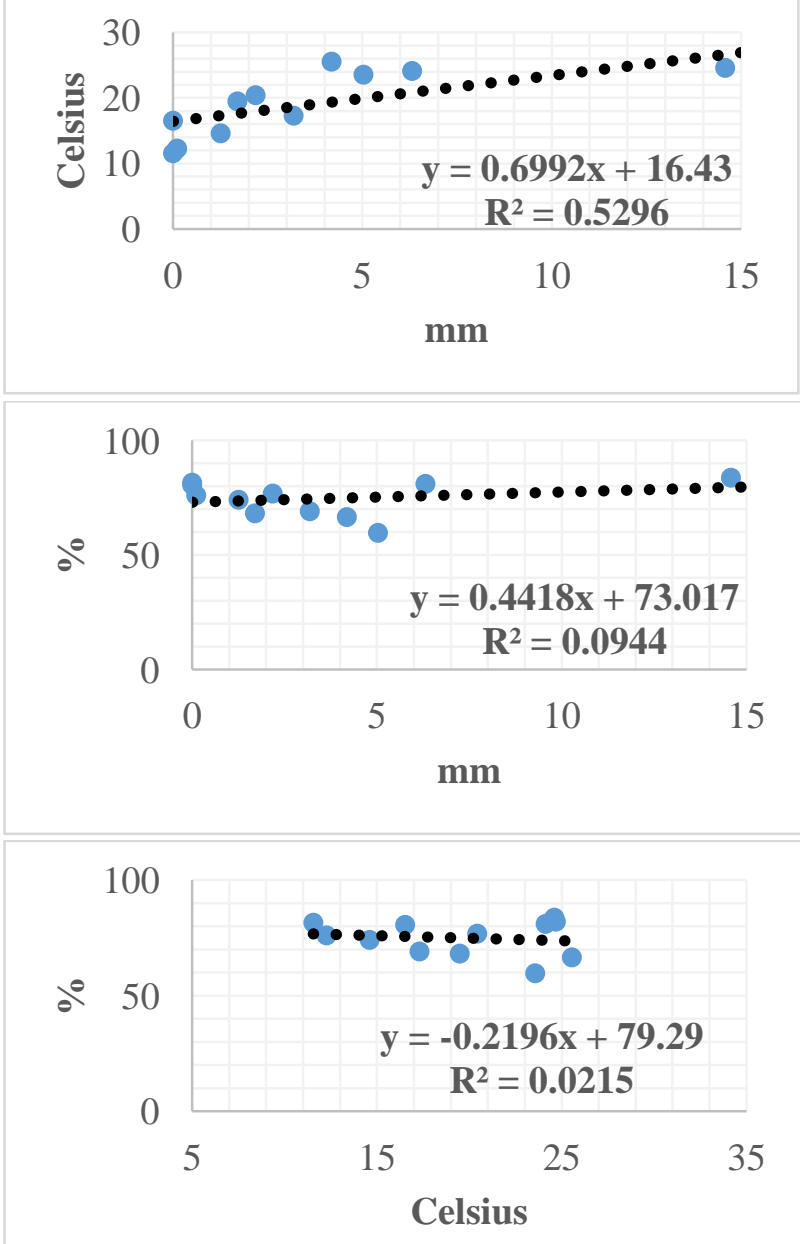

Fig. 5: Shows the correlation between Rainfall vs Temp, Rainfall vs RH and RH vs Temp for the year 2015

Here in figure 6 we can see the correlation between Rainfall vs Temperature, Rainfall vs RH, RH vs Temperature for the year 2016. The first graph is the correlation between Rainfall in $\mathrm{X}$-axis and Temperature in $\mathrm{Y}$-axis is 0.666 , which has the $\mathrm{p}$ value of 0.018 which is less than the significance level $\alpha$ (0.05) which further reject the null hypothesis stating that the correlation between them is significant moderate positive correlation. The second graph is the correlation between Rainfall in $\mathrm{X}$-axis and Relative Humidity in Y-axis is 0.464 , which has $\mathrm{p}$-value of 0.128 which is greater than the significance level $\alpha(0.05)$ which further does not reject the null hypothesis stating that the correlation between them is insignificant low positive correlation. The third graph is the correlation between Temperature in $\mathrm{X}$-axis and Relative Humidity in Y-axis is -0.054 , which has the p-value of 0.867 which is greater than the significance level $\alpha(0.05)$ which further does not reject the null hypothesis stating that the correlation between them is insignificant negligible negative correlation.

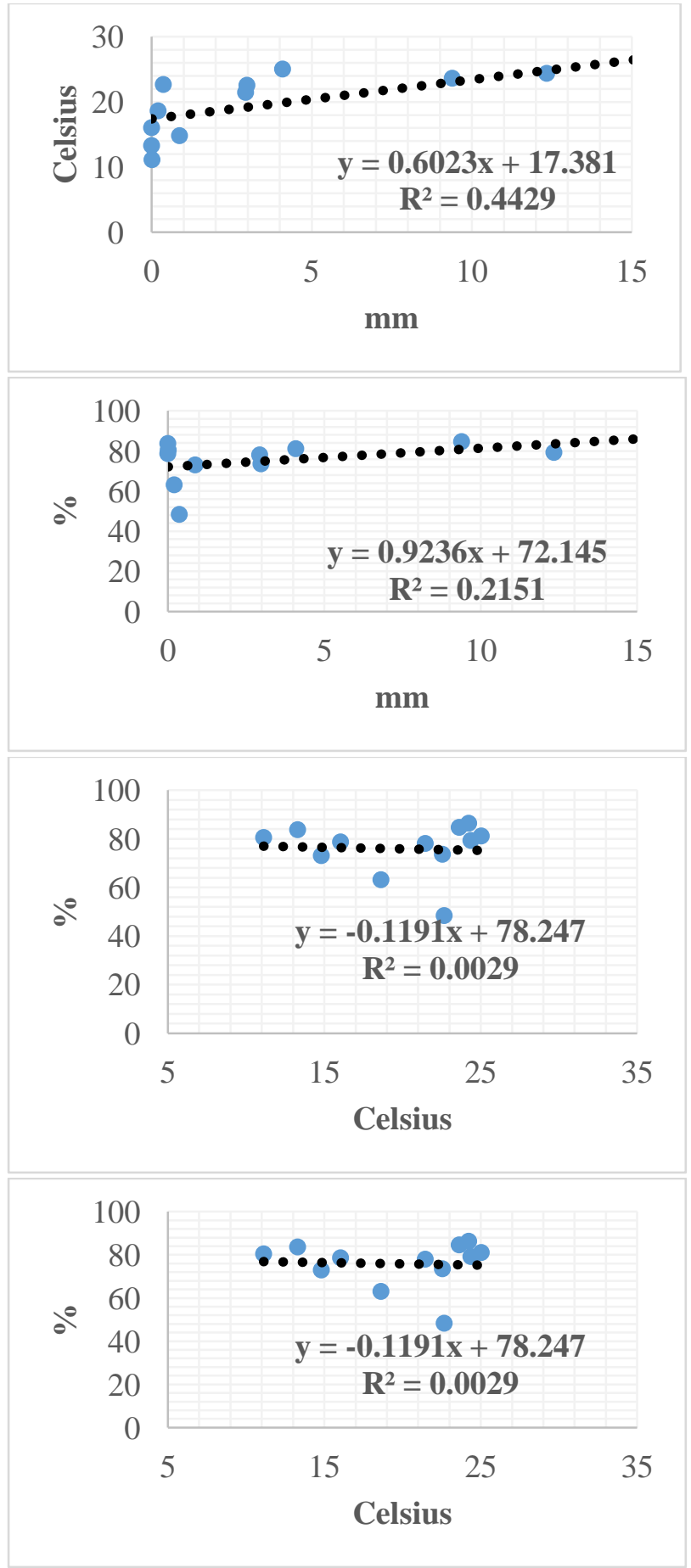

Fig. 6: Shows the correlation between Rainfall vs Temp, Rainfall vs RH and RH vs Temp for the year 2016 
Table 1: Monthly average data of rainfall, Relative Humidity and Temperature from the year 2012-2016.

\begin{tabular}{|c|c|c|c|}
\hline \multicolumn{4}{|c|}{2012} \\
\hline Months & $\begin{array}{c}\text { Rainfall } \\
(\mathbf{m m})\end{array}$ & $\begin{array}{c}\text { Temp } \\
\text { (Celsius) }\end{array}$ & $\begin{array}{c}\text { Humidity } \\
(\%)\end{array}$ \\
\hline January & 0.574 & 10.097 & 77.898 \\
\hline February & 1.441 & 13.976 & 68.940 \\
\hline March & 0.503 & 17.487 & 57.244 \\
\hline April & 2.670 & 20.803 & 58.258 \\
\hline May & 1.361 & 23.711 & 61.768 \\
\hline June & 4.973 & 25.673 & 69.233 \\
\hline July & 14.590 & 24.737 & 84.790 \\
\hline August & 9.342 & 24.835 & 86.090 \\
\hline September & 12.073 & 24.198 & 83.962 \\
\hline October & 0.426 & 19.971 & 75.773 \\
\hline November & 0.023 & 14.513 & 75.475 \\
\hline December & 0.000 & 11.639 & 80.845 \\
\hline \multicolumn{4}{|c|}{2013} \\
\hline Months & $\begin{array}{c}\text { Rainfall } \\
(\mathbf{m m})\end{array}$ & $\begin{array}{c}\text { Temp } \\
\text { (Celsius) }\end{array}$ & $\begin{array}{c}\text { Humidity } \\
(\%)\end{array}$ \\
\hline January & 0.371 & 10.223 & 74.434 \\
\hline February & 1.621 & 14.945 & 70.396 \\
\hline March & 0.881 & 19.103 & 63.324 \\
\hline April & 1.483 & 20.855 & 57.827 \\
\hline May & 8.987 & 23.531 & 66.903 \\
\hline June & 9.970 & 25.028 & 81.818 \\
\hline July & 13.823 & 24.900 & 84.127 \\
\hline August & 14.561 & 24.905 & 86.094 \\
\hline September & 7.243 & 24.342 & 80.603 \\
\hline October & 3.087 & 21.273 & 81.223 \\
\hline November & 0.000 & 15.152 & 80.518 \\
\hline December & 0.000 & 11.789 & 82.971 \\
\hline \multicolumn{4}{|c|}{2014} \\
\hline Months & $\begin{array}{c}\text { Rainfall } \\
(\mathbf{m m})\end{array}$ & $\begin{array}{c}\text { Temp } \\
\text { (Celsius) }\end{array}$ & $\begin{array}{c}\text { Humidity } \\
(\%)\end{array}$ \\
\hline January & 0.135 & 11.256 & 78.121 \\
\hline February & 0.954 & 13.248 & 72.998 \\
\hline March & 1.894 & 17.453 & 66.566 \\
\hline April & 0.200 & 20.745 & 49.740 \\
\hline May & 4.952 & 23.074 & 62.116 \\
\hline
\end{tabular}

\begin{tabular}{|l|l|l|l|}
\hline June & 5.527 & 25.298 & 75.793 \\
\hline July & 14.900 & 25.218 & 83.955 \\
\hline August & 9.500 & 24.968 & 86.360 \\
\hline September & 9.313 & 23.713 & 82.708 \\
\hline October & 2.942 & 20.065 & 79.156 \\
\hline November & 0.000 & 16.015 & 84.347 \\
\hline December & 1.184 & 12.423 & 81.560 \\
\hline \multicolumn{5}{|c|}{$\mathbf{2 0 1 5}$} \\
\hline Months & \multicolumn{1}{|c|}{$\begin{array}{c}\text { Rainfall } \\
\text { (mm) }\end{array}$} & \multicolumn{1}{|c|}{ Temp } & Humidity \\
\hline January & 0.110 & 12.274 & 76.092 \\
\hline February & 1.257 & 14.605 & 74.155 \\
\hline March & 3.184 & 17.305 & 69.142 \\
\hline April & 1.700 & 19.483 & 68.230 \\
\hline May & 5.029 & 23.566 & 59.705 \\
\hline June & 4.187 & 25.552 & 66.588 \\
\hline July & 15.181 & 24.685 & 82.052 \\
\hline August & 14.581 & 24.603 & 83.779 \\
\hline September & 6.313 & 24.130 & 81.087 \\
\hline October & 2.181 & 20.427 & 76.852 \\
\hline November & 0.000 & 16.528 & 80.667 \\
\hline December & 0.000 & 11.561 & 81.587 \\
\hline \multicolumn{5}{|l|}{$\mathbf{2 0 1 6}$} \\
\hline Months & $\begin{array}{c}\text { Rainfall } \\
(\mathbf{m m})\end{array}$ & $\begin{array}{c}\text { Temp } \\
(\text { Celsius })\end{array}$ & Humidity \\
\hline January & 0.013 & 11.126 & 80.511 \\
\hline February & 0.872 & 14.812 & 73.053 \\
\hline March & 0.203 & 18.624 & 63.131 \\
\hline April & 0.367 & 22.667 & 48.380 \\
\hline May & 2.977 & 22.553 & 73.600 \\
\hline June & 12.340 & 24.375 & 79.290 \\
\hline July & 15.413 & 24.232 & 86.373 \\
\hline August & 4.090 & 25.037 & 81.142 \\
\hline September & 9.390 & 23.627 & 84.678 \\
\hline October & 2.935 & 21.455 & 78.055 \\
\hline November & 0.000 & 16.042 & 78.693 \\
\hline December & 0.000 & 13.297 & 83.726 \\
\hline
\end{tabular}


Table 2: Correlation between the parameters from year 2012-2016.

\begin{tabular}{|c|c|c|c|}
\hline 2012 & Correlation & P-Value & Remark \\
\hline $\begin{array}{l}\text { Rainfall Vs } \\
\text { Rh }\end{array}$ & 0.564 & 0.055882 & $\mathrm{p} \geq \alpha$ \\
\hline $\begin{array}{l}\text { Rainfall Vs } \\
\text { Temp }\end{array}$ & 0.689 & 0.013275 & $\mathrm{p}<\alpha$ \\
\hline $\begin{array}{l}\text { Rh Vs } \\
\text { Temp }\end{array}$ & 0.047 & 0.884952 & $p \geq \alpha$ \\
\hline 2013 & Correlation & P-value & Remark \\
\hline $\begin{array}{l}\text { Rainfall Vs } \\
\text { Rh }\end{array}$ & 0.445 & 0.146902 & $\mathrm{p} \geq \alpha$ \\
\hline $\begin{array}{l}\text { Rainfall Vs } \\
\text { Temp }\end{array}$ & 0.818 & 0.001139 & $\mathrm{p}<\alpha$ \\
\hline $\begin{array}{l}\text { Rh Vs } \\
\text { Temp }\end{array}$ & 0.134 & 0.677837 & $\mathrm{p} \geq \alpha$ \\
\hline 2014 & Correlation & P-value & Remark \\
\hline $\begin{array}{l}\text { Rainfall Vs } \\
\text { Rh }\end{array}$ & 0.416 & 0.178518 & $\mathrm{p} \geq \alpha$ \\
\hline $\begin{array}{l}\text { Rainfall Vs } \\
\text { Temp }\end{array}$ & 0.771 & 0.003308 & $\mathrm{p}<\alpha$ \\
\hline $\begin{array}{l}\text { Rh Vs } \\
\text { Temp }\end{array}$ & 0.001 & 0.998279 & $\mathrm{p} \geq \alpha$ \\
\hline 2015 & Correlation & P-value & Remark \\
\hline $\begin{array}{l}\text { Rainfall Vs } \\
\text { Rh }\end{array}$ & 0.307 & 0.331227 & $\mathrm{p} \geq \alpha$ \\
\hline $\begin{array}{l}\text { Rainfall Vs } \\
\text { Temp }\end{array}$ & 0.728 & 0.007301 & $\mathrm{p}<\alpha$ \\
\hline $\begin{array}{l}\text { Rh Vs } \\
\text { Temp }\end{array}$ & -0.147 & 0.649023 & $p \geq \alpha$ \\
\hline 2016 & Correlation & P-value & Remark \\
\hline $\begin{array}{l}\text { Rainfall Vs } \\
\mathrm{Rh}\end{array}$ & 0.464 & 0.128818 & $\mathrm{p} \geq \alpha$ \\
\hline $\begin{array}{l}\text { Rainfall Vs } \\
\text { Temp }\end{array}$ & 0.666 & 0.018167 & $\mathrm{p}<\alpha$ \\
\hline $\begin{array}{l}\text { Rh Vs } \\
\text { Temp }\end{array}$ & -0.054 & 0.867306 & $p \geq \alpha$ \\
\hline
\end{tabular}

\section{CONCLUSION}

Time series analysis helped us to find the monthly relationship between Rainfall, temperature, and relative humidity which were discovered to be consistent throughout five years. High rainfall in June and July, and low rainfall in November, December, January, and February were recorded throughout five years. Similarly, high temperatures were recorded in June, July, and August, while low temperatures were recorded in January and February. When we looked at the graph for relative humidity, we saw a flat line for the bulk of the months, but a decrease in March, April, and May. Using statistical tool, we discovered that in all fiveyear correlations between relative humidity and temperature, rainfall and relative humidity were inconsequential, whereas rainfall versus temperature was significant. The general study of meteorological parameters was done to see if there was any change in the yearly cycle, which came to be false.

\section{ACKNOWLEDGEMENT}

The author would like to express gratitude to Meteorology and Hydrology Department of Government of Nepal for the excess of data. Authors also would like to express gratitude to all the Professors Department of Physics, St. Xavier's College for their valuable suggestions.

\section{REFERENCCES}

[1] Shrestha, A. B; Wake, C. P.; Dibb, J. E.; Mayewski, A. P. Precipitation fluctuations in the Nepal Himalaya and its vicinity and relationship with some large scale climatological parameters, International Journal of Climatolology, 20(3):.... (2000) .

[2] Hossain, Z. et al. Seasonal variation of Temperature in Dhaka Metropolitan city, Bangladesh, JJEES, 6(2): 93-97 (2014).

[3] Precht, H.; Bruck, K. and Precht, H. Temperature and life, Springer, Berlin, Heidelberg (1973).

[4] Michalski, L. et al. Temperature measurement, Measurement Science and Technology, 13:1651 (2002).

[5] Zakaria, J. everything you need to know about interpreting correlations (2019)

[6] Hans-Beat, B. and Jack, D. D. Structure correlation, Wiley. p. 936 (2008).

[7] Benesty, J.; Chen, J.; Huang, Y.; Cohen, I. Pearson Correlation Coefficient. In: Noise Reduction in Speech Processing. Springer. 2: 3740 (2009).

[8] Schober, P.; Boer, C.; and Schwarte, L. A. Correlation Coefficients: Appropriate Use and Interpretation, Anesthesia \& Analgesia, 126(5): 1763-1768 (2018).

[9] Morrison, D. E. and Henkel, R. E. The significance test controversy: A reader. Routledge, p. 352 (2006). 
[10] Kim, T. K. T-test as a parametric statistic, Korean Journal of anesthesiology. 68(6): 540-546 (2015).

[11] Doug, S. Tests and measurements: The Ttest, Strength \& Conditioning, 12(1): 36-37 (1990).

[12] Oyewole, J. A. et al. Variation of Rainfall and Humidity in Nigeria, Journal of Environment and Earth science, 4 (2):... (2014).

[13] Gwani, M. et al. Analysis of Monthly Variation of Relative Humidity and Temperature of Sokoto, Nigeria, World $J$ of Engineering and Pure and Applied Sci, 3(1): 12 (2013).

[14] Steiner, M. and Houze, Jr. R.A. Sensitivity of estimated monthly convective rain fraction to the choice of Z-R relation. J Appl. Meteor., 36: 452462 (1997).

[15] Houze, Robert A., Jr. Stratiform Precipitation in Regions of Convection: A Meteorological Paradox, Bulletin of the American Meteorological Society, 78(10): 2179-2196 (1997).

[16] Lide, D. CRC Handbook of Chemistry and Physics. Boca Raton: CRC Press (2005).

[17] Steadman et al. The Assessment of Sultriness. Part I: A Temperature-Humidity Index Based on Human Physiology and Clothing Science. Journal of Applied Meteorology, 18(7):... (1979)

[18] Kent, A. C. and Howard, N. R. Psychrometer for measuring the humidity of a gas flow, U.S. Patent No. 4,461,167. 24 (1984).

[19] Mohammadkhani, M.; Khanjani, N.; Bakhtiari, B.; Tabatabai, S. M. and Sheikhzadeh, K. The Relation Between Climatic Factors and Malaria Incidence in Sistan and Baluchestan, Iran. SAGE Open, 9(3): ... (2019).

[20] Kilian, A. H. D. et al. Rainfall pattern, El Niño and malaria in Uganda, Transactions of the Royal Society of Tropical Medicine and Hygiene, 93(1): 22-23 (1999). 